\title{
Knowledge and Awareness of Colorectal Cancer among University Students in Oman
}

\author{
Rajani Ranganath, MBBS, M.D. ${ }^{1}$, Lujaina Salim Saud Al-maamari, M.D. ${ }^{2}$, \\ Amnia Ali Rashid Al Saidi, M.D. ${ }^{2}$, Ali Haider Baquer Al Dujaili, M.D. ${ }^{2}$, \\ Mohammed Al-Fatih Mahmood, M.D. ${ }^{2}$
}

'Department of Pathology, College of Medicine and Health Sciences, National University of Science and Technology, Sohar 391, P.C 321 Sultanate of Oman.

${ }^{2}$ Undergraduate medical student, College of Medicine and Health Sciences, National University of Science and Technology, Sohar 391, P.C 321 Sultanate of Oman.

Received 23 December 2020 • Revised 18 May 2021 • Accepted 18 May 2021 • Published online 1 September 2021

\begin{abstract}
:
Objective: Colorectal cancer (CRC) is one of the top ranked cancers in Oman and the incidences of CRC have been dramatically increasing in recent times. The aim of the study was to assess the level of knowledge of $\mathrm{CRC}$ and to understand the level of awareness on CRC screening methods among undergraduate medical students.
\end{abstract}

Material and Methods: This was a cross-sectional study conducted in College of Medicine and Health Sciences, Oman among the undergraduate medical students. The study was a survey based on a questionnaire consisting of 27 items that addressed general risk factors, dietary risk factors, signs and symptoms, screening, and prognostic factors of CRC. Statistical analysis was done using SPSS version 22.

Results: A total of three hundred and eighty-two $(n=382)$ students from the premedical $(45,11.8 \%)$, preclinical $(249$, $65.2 \%)$ and clinical $(88,23.0 \%)$ years participated in the survey. In all the five categories, general risk factors, dietary risk factors, signs and symptoms, screening and prognostic factors, the clinical students had better knowledge and awareness compared to the lower academic year students.

Conclusion: There was low level of awareness among the premedical students, and had shown increased level of awareness in subsequent academic years. Undergraduate teachings should focus more on factual knowledge, skills, and

Contact: Rajani Ranganath, MBBS, M.D.

Department of Pathology, College of Medicine and Health Sciences,

National University of Science and Technology, Sohar 391, P.C 321 Sultanate of Oman.

E-mail: rajaniranganath@nu.edu.com

This is an open access article under the CC BY-NC-ND license

(http://www.jhsmr.org/index.php/jhsmr/about/editorialPolicies\#openAccessPolicy).

J Health Sci Med Res 2022;40(2):215-222 doi: $10.31584 /$ jhsmr.2021835 www.jhsmr.org 
screening for colon cancer. Students need to actively participate in public awareness about CRC through community programs in order to boost their knowledge. These initiatives by students can bring about changes in society as well.

Keywords: colorectal cancer, risk factors, screening program, undergraduate medical students

\section{Introduction}

Colorectal cancer $(\mathrm{CRC})$ is the one of the leading causes of cancer-associated deaths globally. It is one of the top ranked cancers in Oman. In several Gulf countries, such as Oman, Qatar, and Saudi Arabia, the incidence of $\mathrm{CRC}$ in people under 40 years of age has been found to be relatively high. ${ }^{1}$

The rate of mortality in Oman due to cancer has increased during the last decade. According to the Cancer Registry (Ministry of Health), in 2015, the crude incidence rates for all cancers among Omanis were 63.91 per 100,000 for males and 74.88 per 100, 000 for females. CRC ranked first among the male population with a frequency of 82 and incidence rate of 10.95 . $^{2}$

The risk of developing CRC is affected by environmental and genetic factors and personal history, and includes such things as low socioeconomic status, physical inactivity, unhealthy diet, smoking, obesity, and inflammatory bowel disease. ${ }^{3}$ Although genetic risk factors cannot be changed, dietary and environmental factors can be modified to reduce $\mathrm{CRC}$ risk

Most CRCs develop from primary tumours such as adenomatous polyps. Chronic inflammatory bowel diseases and family history of $\mathrm{CRC}$ play important roles in developing CRC. Individuals with a family history of CRC have a 2.5 to 3 times greater risk of developing cancer. ${ }^{4}$

Regular health check-ups and screening help in the early diagnosis of colon cancer. Routine screening can help identify precancerous polyps or abnormal growths in the colon or rectum, allowing their removal at an early stage before they progress into cancer. Symptoms go unnoticed in the early stages of colon cancer and they tend to appear as the cancer progresses. CRC screening should start at age 45, as recommended by the American Cancer Society for detection of $\mathrm{CRC}{ }^{5}$

Barriers to $\mathrm{CRC}$ screening include lack of a provider recommendation, lack of awareness of the need to be screened, fear, expense, competing priorities, inability to take time off work if referred for a colonoscopy, and the perceived undesirable nature of screening tests. ${ }^{6}$

Creating awareness of the risk factors and screening procedure for $\mathrm{CRC}$ can play a crucial role in curbing the incidences of cancer. Hence this study was done to assess the level of knowledge and awareness of CRC among the undergraduate medical students from the College of Medicine, National University of Science and Technology in order to provide data to assist in planning appropriate changes to the related curricula and promoting communitybased educational activities.

The objective of the study was: Assess the level of knowledge of $\mathrm{CRC}$ and to understand the level of awareness on $\mathrm{CRC}$ screening methods among undergraduate medical students.

\section{Material and Methods}

This was a cross-sectional study conducted with undergraduate medical students at the National University of Science and Technology, College of Medicine and Health Sciences, Oman in 2019. The proposed study was reviewed and approved by the Research and Ethics Committee of COMHS (Register No: CMHS/REC/015/18/C). Convenience sampling was done, and 382 students were included who agreed to participate for the study. 
The purpose of the study and instructions related to completing the survey forms were explained, and a selfadministered questionnaire created through Google Forms sent to the participant's emails.

The questionnaire was developed after reviewing several similar studies. The questionnaire was designed to address the respondents' knowledge on colon cancer and their awareness of CRC screening among undergraduate students. The content and validity of the questionnaire were evaluated using a Likert scale for relevance, clarity, grammar/spelling, ambiguity, and sentence structure by six subject experts at the university. The experts were given a cover letter explaining the purpose of the study, a description of the questionnaire and an explanation on the content evaluation procedure. The experts were asked to score each question as follows: Strongly agree -5 , Agree -4 , Neutral -3 , Disagree -2 and Strongly disagree -1 . The questions that got the lowest scores were asked for deletion or revision. The six participants (students) evaluated the questionnaire for feasibility, simplicity, and time required to answer the questionnaire stated that the questionnaire was easy to understand and easy to fill.The Item-Content Validity Index (I-CVI) estimations for the 27 items ranged between 0.78 and 1.00 and were retained after the evaluation of the panelists, indicating that these items were considered clear, understandable, and relevant to the questionnaire. The modified Kappa $\left(\mathrm{K}^{\star}\right)$ values for all items were excellent $(>0.75)$ and the Scale Content Validity Index (S-CVI/Ave) was 0.89 , confirming the content validity of the questionnaire. The internal consistency of questionnaire, Cronbach's alpha was 0.785 .

The questionnaire consisted of 27 items distributed in five sections. Section 1 consisted of eight questions that focused on the general risk factors for development of $\mathrm{CRC}$, section 2 had four questions on dietary risk factors for development of $\mathrm{CRC}$, section 3 had five questions on the signs and symptoms of $\mathrm{CRC}$, section 4 had four questions on screening for $\mathrm{CRC}$ and section 5 consisted of six questions on the prognostic factors of CRC. The questions were all answered by yes, no or do not know. For each right answer a score of ' 1 ' was given, for a wrong or don't know answer the score was ' 0 '. The overall total sore and the scores for each domain were calculated. An overall score of less than 13 was considered low and 14-27 was considered high.

Data were analyzed using SPSS version 22. Descriptive statistics (The frequency with percentages and mean for categorical variables) were used for the study variables, and chi-square(X2) test was applied to establish statistical significance.

\section{Results}

A total of three hundred and eighty-two $(n=382)$ students from the premedical $(45,11.8 \%)$, preclinical $(249$, $65.2 \%)$ and clinical $(88,23.0 \%)$ years participated in the survey. Three hundred and fifty-two students (92.1\%) were female and thirty $(7.9 \%)$ were male (Table 1$)$.

Table 2 shows, $73.3 \%$ of students with low knowledge score were premedical students and the percentage of students with high score has increased in the successful academic years with highest in clinical year's student $(87.0 \%)$. The average mean score was high in clinical year's students 16.50 when compared to premedical and preclinical years. The knowledge score across the different academic years was found to be statistically significant with p-value $<0.001$.

The mean was 13.97 among male students and 14.5 for female students, comparatively higher among female students but not statistically significant ( $p-v a l u e=0.662)$. 
Table 1 Demographic characteristics

\begin{tabular}{|c|c|c|c|c|c|c|c|c|}
\hline \multirow{3}{*}{ Gender } & \multicolumn{8}{|c|}{ Students } \\
\hline & \multicolumn{2}{|c|}{ Premedical } & \multicolumn{2}{|c|}{ Preclinical } & \multicolumn{2}{|c|}{ Clinical } & \multicolumn{2}{|c|}{ Total } \\
\hline & Number & $\%$ & Number & $\%$ & Number & $\%$ & Number & $\%$ \\
\hline Female & 41 & 91.1 & 232 & 93.2 & 79 & 89.8 & 352 & 92.1 \\
\hline Male & 4 & 8.9 & 17 & 6.8 & 9 & 10.2 & 30 & 7.9 \\
\hline Total & 45 & 100 & 249 & 100 & 88 & 100 & 382 & 100 \\
\hline
\end{tabular}

Table 2 Knowledge score percentage distribution of medical students

\begin{tabular}{llll}
\hline $\begin{array}{l}\text { Knowledge } \\
\text { score }\end{array}$ & $\begin{array}{l}\text { Premedical } \\
\text { students } \\
(\%)\end{array}$ & $\begin{array}{l}\text { Preclinical } \\
\text { students } \\
(\%)\end{array}$ & $\begin{array}{l}\text { Clinical } \\
\text { students } \\
(\%)\end{array}$ \\
\hline Low & 73.3 & 36.1 & 12.5 \\
high & 26.7 & 63.9 & 87.5 \\
\hline & 100 & 100 & 100 \\
\hline
\end{tabular}

Table 3 shows that the knowledge of general risk factors for colon cancer was higher among the clinical year students. The knowledge score for general risk factors across the years was statistically significant. There was not much difference between the premedical and preclinical years with $p$-value $=0.708$.

Table 3 General risk factors- knowledge score among students of different academic years

\begin{tabular}{llll}
\hline Students & Number & Mean & p-value \\
\hline Premedical & 45 & 3.62 & \\
Preclinical & 249 & 3.82 & $<0.001$ \\
Clinical & 88 & 4.90 & \\
\hline Total & 382 & 4.05 & \\
\hline
\end{tabular}

As shown in Table 4, the knowledge of dietary risk factors that can cause colon cancer was found to be high in the clinical year students. The preclinical students had slightly better knowledge than the premedical year students, but the difference was not statistically significant. ( $p-$ value $=0.552)$.

Table 4 Dietary risk factors- knowledge score among students of different academic years

\begin{tabular}{llll}
\hline Students & Number & Mean & p-value \\
\hline Premedical & 45 & 1.51 & \\
Preclinical & 249 & 1.67 & $<0.001$ \\
Clinical & 88 & 2.19 & \\
\hline Total & 382 & 1.77 & \\
\hline
\end{tabular}

Table 5 shows that the knowledge concerning the signs and symptoms of colon cancer was low among premedical students with a mean score of 2.38. The mean score of the premedical students was lower to both preclinical $(p-$ value $=0.020)$ and clinical $(p-$ value $=0.010)$ students. The average mean between preclinical and clinical year students did not show much difference. $(p-$ value $=0.106)$.

Table 5 Signs and symptoms- knowledge score among students of different academic years

\begin{tabular}{llll}
\hline Students & Number & Mean & p-value \\
\hline Premedical & 45 & 2.38 & \\
Preclinical & 249 & 3.01 & $<0.001$ \\
Clinical & 88 & 3.38 & \\
\hline Total & 382 & 3.02 & \\
\hline
\end{tabular}


Table 6 shows that the clinical students had better knowledge about colon cancer screening when compared to the preclinical and premedical students, with statistically significant $p$-values $=0.020$ and $=0.006$ for the preclinical and premedical students, respectively. The average mean between premedical and preclinical was not statistically significant with $\mathrm{p}$-value $=0.329$.

Table 6 Screening of colon cancer- knowledge score among students of different academic years

\begin{tabular}{llll}
\hline Students & Number & Mean & p-value \\
\hline Premedical & 45 & 2.00 & \\
Preclinical & 249 & 2.18 & 0.004 \\
Clinical & 88 & 2.43 & \\
\hline Total & $\mathbf{3 8 2}$ & $\mathbf{2 . 2 1}$ & \\
\hline
\end{tabular}

Table 7 shows that the clinical students had better knowledge on the prognosis of colon cancer than both premedical and preclinical students with $p$-value $<0.001$ The average mean score of preclinical students was high when compared to premedical students ( $p-v a l u e=0.006)$.

Table 7 Prognostic factors- knowledge score among students of different academic years

\begin{tabular}{llll}
\hline Students & Number & Mean & p-value \\
\hline Premedical & 45 & 1.38 & \\
Preclinical & 249 & 2.21 & $<0.001$ \\
Clinical & 88 & 3.50 & \\
\hline Total & 382 & 2.41 & \\
\hline
\end{tabular}

\section{Discussion}

This study intended to understand the level of knowledge and awareness of CRC among our medical students. It was observed that the knowledge on CRC increased with advancing academic year. The premedical students had low knowledge, which improved in the preclinical year students and still higher in the clinical year students similar findings were observed in a study conducted by Villareal-Garza et al. ${ }^{7}$ In our study $73.3 \%$ of the premedical students had low levels of knowledge and $87.5 \%$ of the clinical year students had high levels of knowledge. This was comparatively higher than the study by Min-Yi Wang et al. ${ }^{8}$ A study by Loo et al showed $64.9 \%$ of university students had low levels of knowledge and female students had higher levels of knowledge than males ${ }^{9}$; female students performed better than males in our study.

A shortage of specialist doctors and inadequate promotion of community awareness program could be the reason for lack of awareness about $\mathrm{CRC}$ and screening modalities among patients; these barriers could certainly be associated with insufficient knowledge among this sample of students representing the population. A community-based survey on colon cancer conducted in Oman found that most people were unaware of modifiable risk factors, with more highly educated people having better knowledge than other groups. ${ }^{10}$ Knowledge about CRC screening among medical students was inadequate ${ }^{11}$; similar finding were observed in the current study, premedical students had low knowledge of CRC.

Smoking, alcohol intake, increased body weight and inflammatory bowel diseases such as ulcerative colitis are important risk factors in the development of CRC. Non-modifiable risk factors include family history of CRC or genetic mutations. Clinical year students were aware of these risk factors with a mean score of 4.90 when compared to premedical and preclinical who had mean scores of 3.62 and 3.82, respectively. Regarding knowledge of CRC risk factors, clinical year students in our study $(61.2 \%)$ had better knowledge when compared to $36.1 \%$ poor knowledge and $47.4 \%$ fair knowledge in a study conducted at Jordan. ${ }^{12}$

Diet plays a very important role in maintaining a heathy gut. Red meat intake, alcohol intake, and low 
intake of vegetable and fruit are reasonably associated with increased risk of CRC. Antioxidants such as Vitamins A, C, and E, Beta carotene and selenium, calcium and fish oil are all protective against CRC. It is a matter of concern to see that most of the students were not aware of these dietary factors. The rates of correct answers on dietary risk factors were $38.4 \%, 42.6 \%$ and $54.8 \%$ among the premedical, preclinical and clinical years, respectively. Wang et al study also showed students had sufficient knowledge about dietary factors that influence CRC. ${ }^{13}$ Another study conducted in a primary care setting for general public by the Muscat governorate found that most of them were not aware of heathy eating habits as being protective against CRC. ${ }^{14}$

The current incidence of CRC is high in Oman, and is increasing every year both here and in the other Gulf Cooperation Council countries. Ignorance of the CRC risk factors could be one of the reasons for this fact.

Awareness of signs and symptoms is important in prevention of CRC. Earlier the cancer is detected better will be the long-term prognosis. The warning signs of CRC that need to be watched for are a change in bowel habits that lasts for more than a few days, rectal bleeding with bright red blood, dark stool, cramping or abdominal pain and unintended weight loss. The preclinical and clinical year students had better knowledge of the signs and symptoms of $\mathrm{CRC}$ with correct answers response of $60.6 \%$ and $67.5 \%$, respectively. This was comparable with Mansour-Ghanaei et al. study. ${ }^{15}$

CRC screening plays an important role in reducing mortality. Oman reports CRC as the second-most common cancer (10.9\%) among males, the third among females $(7.5 \%)$ and about $11.2 \%$ of the total global cancer incidence. Low prevalence of screening may be due to less motivational activities organized by the local government and also may be due educational barriers and behavioural patterns among the population. ${ }^{16} \mathrm{CRC}$ screen- ing program can be augmented by educating health care students and personnel's about the relevant tests and their appropriate application. It is advisable that these medical students, as future physicians, should develop skills and adopt appropriate guidelines early in their careers. Hence imparting knowledge about screening practices and guidelines for $\mathrm{CRC}$ will help to prevent the risk and minimize the future burden of CRC.

Regular CRC screening should begin no later than the age of 50 , and should be done regularly by an appropriate method up to 75 years of age. Screening tests like faecal occult blood tests should to be done every year as part of a yearly check-up and a colonoscopy should be done every 10 years. ${ }^{17}$ In the present study knowledge of $\mathrm{CRC}$ screening increased progressively with succeeding academic years, an average correct response rate of $66.1 \%$ among the clinical year students, $50.5 \%$ and $55.7 \%$ in the premedical and preclinical students, respectively; similar findings have been documented in Boehler et al. study. ${ }^{18}$

Lack of awareness, inadequate knowledge of CRC, and not recognizing $\mathrm{CRC}$ as a serious health problem are barriers to screening for $\mathrm{CRC}$. $^{19}$ Recognizing the knowledge deficit of medical students could help teachers to incorporate the important information about CRC and improve teaching strategies to enhance student learning outcomes. ${ }^{20}$

Old age, male gender, ulcerative type lesions, polypoid lesions, involvement of adjacent structures and lymph nodes and carcinoembryonic antigen (CEA) levels are all the factors that influence the prognosis of $\mathrm{CRC}$. $^{21}$ The pathological features, size and type of the primary tumour and lymph node involvement were linked with survival outcome. $^{22}$ The knowledge of prognostic factors was high in our study in the clinical year students. The rate of correct answers was very low among the premedical students at $22.8 \%$, and increased with the advancement of academic year to $37.7 \%$ in the preclinical and $60.1 \%$ in the clinical year students. 
Higher survival rates in CRC patients with higher level of education can be attributed to their awareness of the importance of healthy diet and lifestyle. Education level also determines economic status and their ability to access to medical centres is better. Insufficient knowledge and awareness of self-care and screening programs necessitates intervention, control, and prevention programs. $^{23}$

The incidence of CRC in Oman is increasing and not enough national screening programs for CRC are being conducted regularly. Incorpoartion of health promotion and strengthening the awareness of $\mathrm{CRC}$ through education and screening modalities in the curriculum of medical schools will become crucial. ${ }^{20,24}$

In our study both premedical and preclinical students had inadequate knowledge of $\mathrm{CRC}$ and its screening methods, which may be because of less exposure to clinical training when compared to clinical year students.

The present study highlights the gap in the knowledge of colon cancer among the medical students. The educators need to take corrective measures for overall improvement in knowledge and emphasize awareness on screening methods of CRC. Medical students are the doctors of tomorrow hence proper training can help them in early diagnosis and this can attribute to better survival of patients.

\section{Conclusion}

The knowledge regarding $\mathrm{CRC}$ and its screening techniques was unsatisfactory, especially among the premedical students, and increase in the level of knowledge was seen in successive years. It is important to review the curriculum and teaching methodologies so that more focus is given for scientific knowledge, practical skills and screening procedures of $\mathrm{CRC}$ in the early academic years. This can also be achieved in every medical institution by promoting $\mathrm{CRC}$ awareness activities involving the students.
Such activities will help students gain practical knowledge and skills and as well benefit the people in the community.

\section{Acknowledgement}

We thank Dr. Rajeev Bajaj from department of physiology for helping us in data collection from the MD4 medical students.

\section{Funding sources}

None

\section{Conflict of interest}

None

\section{References}

1. Al-Lawati NA, Al-Bahrani BJ, Al-Raisi SS, Al-Lawati JA Twenty-year trends of cancer incidence in Omanis, 1996-2015. Oman Med J 2019;34:361-87.

2. Murphy N, Xu L, Zervoudakis A, Xue X, Kabat G, Rohan TE, et al. Reproductive and menstrual factors and colorectal cancer incidence in the Women's Health Initiative Observational Study. Br J Cancer 2017;116:117-25.

3. Patel SG, Ahnen DJ. Prevention of interval colorectal cancers: what every clinician needs to know. Clin Gastroenterol Hepatol 2014;12:7-15.

4. Smith RA, Andrews KS, Brooks D, Fedewa SA, ManassaramBaptiste D, Saslow D, et al. Cancer screening in the United States, 2018: a review of current American Cancer Society guidelines and current issues in cancer screening. CA Cancer J Clin 2018; 68:297-316.

5. Villarreal-Garza C, García-Aceituno L, Villa AR, PerfectoArroyo M, Rojas-Flores M, León-Rodríguez E. Knowledge about cancer screening among medical students and internal medicine residents in Mexico City. J Cancer Educ 2010;25: 624-31.

6. Wang MY, Lin GZ, Li Y, Dong H, Liao YH, Liu HZ, et al. Knowledge, attitudes, preventive practices and screening intention about colorectal cancer and the related factors among residents in Guangzhou, China. Asian Pacific J Cancer Prev 2017;18:3217-23. 
7. Lin Loo J, Yee Woo W, Wah Chin M, Ru Yam H, Kwang Ang Y, Seng Yim H. Cancer Awareness of a Sample of Malaysian Undergraduate Students. Am J Cancer Prev 2013; 1:9-13.

8. Al-Azri M, Al-Rasbi K, Al-Hinai M, Davidson R, Al-Maniri A. Awareness of risk factors for cancer among omani adultsA community based study. Asian Pacific J Cancer Prev 2014; 15:5401-6.

9. Althobaiti A, Jradi H. Knowledge, attitude, and perceived barriers regarding colorectal cancer screening practices and risk factors among medical students in Saudi Arabia. BMC Med Educ 2019;421. doi: 10.1186/s12909-019-1857-7.

10. Mhaidat NM, Al-husein BA, Alzoubi KH, Hatamleh DI, Khader $\mathrm{Y}$, Matalqah $\mathrm{S}$, et al. Knowledge and awareness of colorectal cancer early warning signs and risk factors among university students in Jordan. J Cancer Educ 2018;33:448-56.

11. Wang R, Wang MJ, Ping J. Clinicopathological features and survival outcomes of colorectal cancer in young versus elderly. Med 2015;94:e1402.

12. Al-Azri M, Al-Kindi J, Al-Harthi T, Al-Dahri M, Panchatcharam SM, Al-Maniri A. Awareness of stomach and colorectal cancer risk ractors, symptoms and time taken to seek medical help among public attending primary care setting in muscat governorate, Oman. J Cancer Educ 2019;34:423-34.

13. Mansour-Ghanaei A, Joukar F, Mansour-Ghanaei F, Rasoulian J, Naghipour MR, Fani A, et al. Knowledge about colorectal cancer in Northern Iran: a population-based telephone survey. Asian Pacific J Cancer Prev 2015;16:7831-6.

14. Smith RA, Manassaram-Baptiste D, Brooks D, Doroshenk M, Fedewa S, Saslow D, et al. Cancer screening in the United States, 2015: a review of current American Cancer Society guidelines and current issues in cancer screening. CA Cancer $J$ Clin 2015;65:30-54.

15. Song M, Garrett WS, Chan AT. Nutrients, foods, and colorectal cancer prevention. Gastroenterology 2015;148:1244-60.e16.

16. Scheid DC, Hamm RM, Ramakrishnan K, McCarthy LH, Mold JW. Improving colorectal cancer screening in family medicine: an Oklahoma physicians resource/research network (OKPRN) study. J Am Board Fam Med 2013;26:498-507.

17. Jones RM, Devers KJ, Kuzel AJ, Woolf SH. Patient-reported barriers to colorectal cancer screening. A mixed-methods Analysis. Am J Prev Med 2010;38:508-16.

18. Pietrzyk Ł, Torres A, Denisow-Pietrzyk M, Torres K. What do we know about education in colorectal cancer prevention?Survey among 1130 medical students. J Cancer Educ 2017; 32:406-12.

19. Hill S, Sarfati D, Blakely T, Robson B, Purdie G, Chen J, et al. Survival disparities in Indigenous and non-Indigenous New Zealanders with colon cancer: the role of patient comorbidity, treatment and health service factors. J Epidemiol Community Health 2010;64:117-23.

20. Khayyat YM, Ibrahim EM. Public awareness of colon cancer screening among the general population: a study from the Western Region of Saudi Arabia. Qatar Med J 2014;2014:17.

21. Poornakala S, Prema NS. A study of morphological prognostic factors in colorectal cancer and survival analysis. Indian $\mathrm{J}$ Pathol Microbiol 2019;62:36-42.

22. Hassan MR1, Suan MA, Soelar SA, et al. Survival Analysis and Prognostic Factors for Colorectal Cancer Patients in Malaysia. Asian Pac J Cancer Prev 2016;17:3575-81.

23. Hill S, Sarfati D, Blakely T, Robson B, Purdie G, Chen J, et al. Survival disparities in Indigenous and non-Indigenous New Zealanders with colon cancer: The role of patient comorbidity, treatment and health service factors. J Epidemiol Community Health 2010;64:117-23.

24. Khayyat YM, Ibrahim EM. Public awareness of colon cancer screening among the general population: A study from the Western Region of Saudi Arabia. Qatar Med J 2014;2014:17. 